\title{
MicroscopyAwards
}

\section{Microanalysis Society Awards: 2020 Award Recipients}

\author{
Bradley T. De Gregorio ${ }^{\star \star}$ and Heather Lowers ${ }^{2}$ \\ ${ }^{1}$ U.S. Naval Research Laboratory \\ ${ }^{2}$ U.S. Geological Survey \\ *awards@the-mas.org
}

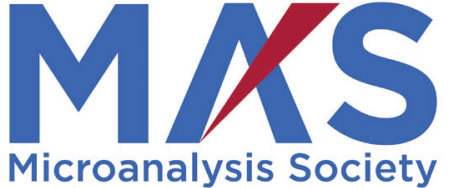

Each year, the Microanalysis Society (MAS) bestows several major awards during the Microscopy \& Microanalysis annual meeting. Regrettably, there is never enough time on stage to detail these awardees' contributions to the science of microanalysis and the Society, which we hope to rectify here and in future articles. The shift of the 2020 M\&M meeting to a virtual format meant that our awardees did not receive their accolades on a physical main stage. These recipients were selected for recognition by a variety of mechanisms, of which many Society members may not be aware. For example, the MAS Awards Committee solicits nominations for annual Outstanding Paper Awards from $M \& M$ meeting attendees and symposium organizers via a simple webform (https://the-mas.org/mm-outstanding-paperrecommendation/), whereas the Duncumb Award requires a full nomination package from Society members, and other awards are selected solely at the discretion of the MAS President or Council. Additional description of the various MAS awards, including lists of previous award winners, can be found at https://the-mas.org/awards.

\section{Duncumb Award}

The Peter Duncumb Award for Excellence in Microanalysis recognizes outstanding achievement by a currently active individual over a sustained period of time in the field of microanalysis through technical accomplishment, leadership, educational activities, and professional activities. The award is sponsored by MAS Sustaining Member Bruker Nano Inc.

\section{Peter Duncumb Award: Nestor Zaluzec}

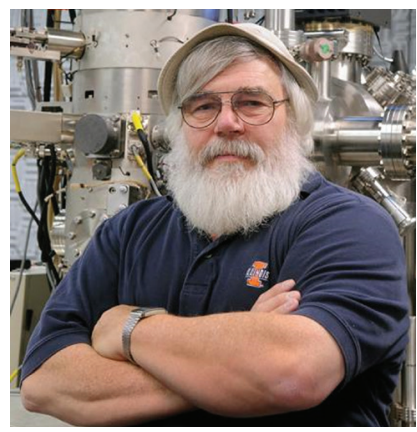

Nestor Zaluzec, Senior Scientist, Electron Microscopy Center, Argonne National Laboratory.
Dr. Zaluzec's microanalytical origins trace back to the early 70s, where, as an undergraduate in Physics at the Illinois Institute of Technology in Chicago and working part-time at the Sherwin Williams Research Center, he designed and built his first instrument, the spectrogoniophotometer. In graduate school at the University of Illinois at UrbanaChampaign with Professor HL Fraser, he switched from light to electrons, where his research included designing hardware and software for quantitative X-ray microanalysis and an early form of scanning diffraction for TEM/STEM. He was awarded the prestigious Eugene P. Wigner Fellowship at Oak Ridge National Laboratory, where he interfaced one of the first EDS systems to a high-vacuum electron microscope and built an aberration-corrected electron spectrometer and associated software. After his fellowship at ORNL, Dr. Zaluzec joined Argonne National Laboratory, where he continued his research and development in both XEDS and EELS, established the Electron Microscopy Center, and became its first Director. At ANL, he built the first CCD detector system for parallel EELS. The now-ubiquitous plasma cleaner for electron microscopes was another of his inventions, as well as the scanning confocal electron microscope and the $\pi$ steradian XEDS detector. His work over the last 30 years has included studies in the areas of structural phase transformation in metals, radiation damage in alloys, ceramic oxides for geologic immobilization of nuclear waste materials, elemental segregation in a wide range of materials ranging from metals and catalysts to semiconductors and superconductors, magnetic dichroism, genetically engineered bio-materials, and, most recently, studies of optical photovoltaics and plasmonics in coupled and hybrid nanostructures. He is currently investigating how aberrationcorrected instruments can be reengineered to improve the sensitivity of spectroscopy in analytical modes.

\section{Heinrich Award}

The KFJ Heinrich Award honors a scientist with less than 15 years from their terminal degree who has made distinguished technical contributions to the field of microanalysis.

\section{KFJ Heinrich Award: Lena Kourkoutis}

Dr. Kourkoutis' research is focused on understanding and controlling nanostructured materials, from quantum materials to materials for energy to biomaterials. She and her electron microscopy group at Cornell University have developed new cryogenic scanning transmission electron microscopy techniques to gain access to low-temperature electronic states, to study processes at liquid/solid interfaces, and to image thick biological specimens. Dr. Kourkoutis received her undergraduate degree in Physics from the University of 


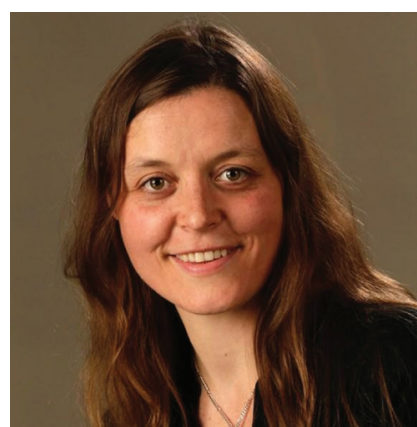

Lena Kourkoutis, James C. and Rebecca Q. Morgan Sesquicentennial Faculty Fellow, School of Applied \& Engineering Physics, Cornell University.

Martinsried, Germany. She returned to Cornell University and joined the Applied and Engineering Physics Faculty in 2013. For her contributions to the field of microscopy, Dr. Kourkoutis was awarded the 2013 Albert Crewe Award and the 2018 Burton Medal from the Microscopy Society of America. She is also the recipient of a 2014 Packard Fellowship for Science and Engineering and a 2016 Presidential Early Career Award for Scientists and Engineers.

\section{Presidential Science Award}

The MAS Presidential Science Award honors a senior scientist for outstanding technical contributions to the field of microanalysis over a sustained period of time.

\section{Presidential Science Award: Gianluigi Botton}

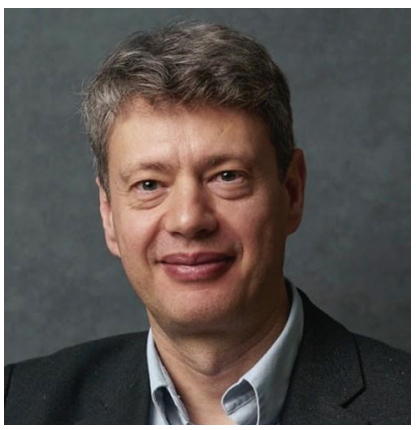

Dr. Botton uses analytical electron microscopy, particularly EELS, to develop novel imaging tools for materials analysis, momentumresolved methods for studying anisotropy in alloys and quantum materials, and nearedge fine structure methods for understanding bonding and electronic structure of solids. More recently, he and his team have focused on atomic-resolved and low-loss spectroscopy to understand plasmon surface resonances

Gianluigi Botton, Canada Research Chair in Microscopy of Electron Materials, Canadian Centre for Electron Microscopy, McMaster University.

in nanostructured materials and application of EELS as a high spatial resolution probe of the behavior of energy materials. Dr. Botton received his undergraduate degree in Engineering Physics and a $\mathrm{PhD}$ in Materials Engineering from Ecole Polytechnique of Montréal under the supervision of Gilles L'Espérance. He was a Postdoctoral Fellow in the Department of Materials Science and Metallurgy at the University of Cambridge from 1993 to 1998 working with Sir Colin Humphreys. He joined the Materials Technology Laboratory of Natural Resources Canada in 1998 as a research scientist working with Graham Carpenter and Tom Malis. In 2001, he moved to the Department of Materials
Science and Engineering at McMaster University, where he holds a Canada Research Chair in Electron Microscopy of Nanoscale Materials. He was the founding director of the Canadian Centre for Electron Microscopy, a national facility for electron microscopy and multiple nano/atomic scale analysis techniques. In May 2019, he became the Science Director at the Canadian Light Source, the largest scientific research facility in Canada, while he continues his research in electron microscopy.

\section{Presidential Service Award}

The MAS Presidential Service Award honors a member of the MAS for outstanding volunteer service to the Society over a sustained period of time.

\section{Presidential Service Award: Edward Vicenzi}

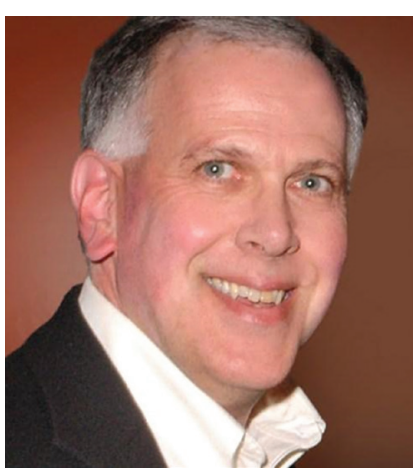

Edward Vicenzi, Research Scientist, Museum Conservation Institute, Smithsonian Institution.
Dr. Vicenzi is a research scientist at the Smithsonian Institution's Museum Conservation Institute (MCI). His work involves using microbeam techniques to understand the history and origin of museum specimens through the investigation of heritage and earth science materials. He obtained a BSc from McGill University, an MS from the University of Oregon, and a PhD from Rensselaer Polytechnic Institute, all in Earth Sciences. Before taking up his position at MCI, he was the Director of the Analytical Laboratories in the National Museum of Natural History's (NMNH) Department of Mineral Sciences, and prior to that the co-manager of the Imaging and Analysis Center at Princeton University.

Dr. Vicenzi has served as President and Director of the Microanalysis Society, principal and co-organizer of several MAS topical conferences, MAS co-chair for the M\&M meeting and organizer of several M\&M symposia, chair of the NMNH Senate of Scientists, and MAS tour speaker. He was inducted as a Fellow of the MAS in 2019. He is the past-president for the International Union of Microbeam Analysis Societies (IUMAS) and served as Chair of the IUMAS- 6 congress. He sits on the editorial board for Heritage Science and is the editor for cultural heritage applications for Microscopy and Microanalysis.

\section{MAS Fellows}

MAS Fellow is a designation that is intended to recognize eminent scientists, engineers, and technologists in the field of microanalysis of materials and related phenomena who have distinguished themselves through outstanding research and service to the microanalysis community. This includes, but is not limited to, technique development, applications, theory development, and distinguished service to the MAS. Election as a MAS Fellow is highly selective $(<0.5 \%$ of the MAS membership per year) and represents a broad 
cross section of members. To be eligible for election as a MAS Fellow, the nominee must be a member of the MAS for a minimum of 10 years and have attended at least 5 MAS or M\&M meetings.

2020 MAS Fellows with Nominating Statement

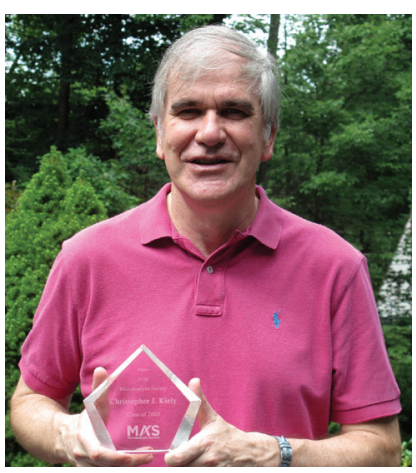

Christopher Kiely, Harold B. Chambers Senior Professor, Lehigh University.

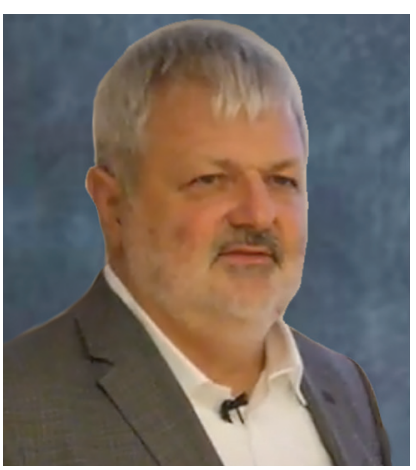

Lothar Strüder, CEO, PNSensor $\mathrm{GmbH}$.

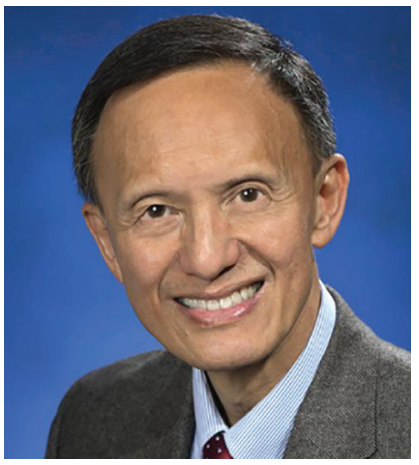

Yimei Zhu, Senior Scientist, Brookhaven National Laboratory.
Christopher Kiely: For outstanding leadership and sustained contributions to analytical electron microscopy of nanoparticle self-assembly, metal and complex oxide catalysts, and interfacial analysis. Dr. Kiely directs the Materials Characterization Facility at Lehigh University and the annual Lehigh Microscopy School. He has a joint appointment as a professor of electron microscopy and catalysis at the Cardiff Catalysis Institute in the UK.

Lothar Strüder: For outstanding leadership and sustained contributions to the development and commercialization of the Silicon Drift Detector for energy-dispersive spectroscopy. Dr. Strüder is CEO of PNSensor GmbH and a Progen. He received the Glenn F. Knoll Radiation Instrument Outstanding Achievement Award in 2019 from the IEEE Nuclear and Plasma Sciences Society.

Yimei Zhu: For outstanding leadership and pioneering development of electron-based techniques for quantitative materials characterization in the study of interfaces, defects, and electronic inhomogeneity of functional materials. Dr. Zhu helped to create the Center for Functional Nanomaterials at Brookhaven National Laboratory. $\mathrm{He}$ is also a Fellow of the MSA, the American Physical Society, and the AAAS. fessor at the University of Sie-

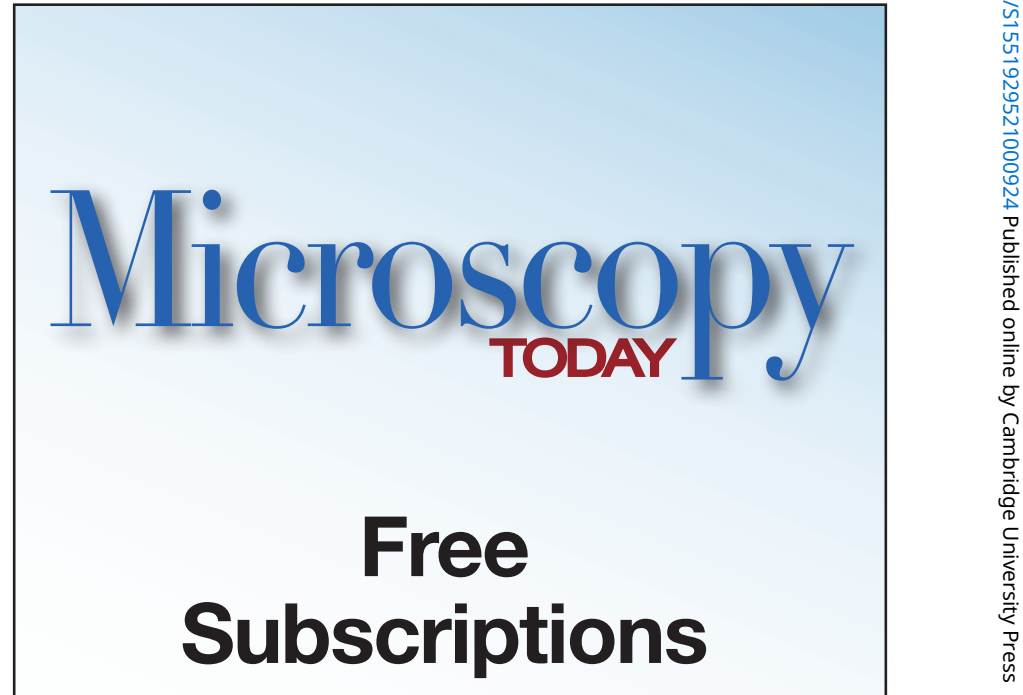

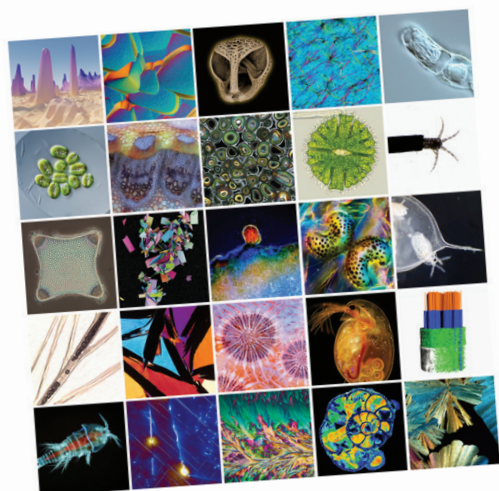

EMSA

$\underset{\text { CAMBRIDGE }}{\text { CAMESTY YMESS }}$

\section{Individuals may request a personal copy at:}

\section{https://www.microscopy.org/publications/} microscopy_today.cfm 